\title{
LA CONSTRUCCIÓN DE LA IDENTIDAD PERSONAL COMO PROYECTO DE EDUCACIÓN MORAL. SUPUESTOS TEÓRICOS Y DELIMITACIÓN DE COMPETENCIAS
}

The construction of personal identity as a project in moral education. Theoretical bypotheses and the definition of competences

La construction de l'identité personnelle comme projet d'éducation morale. Hypothèses théoriques et délimitation de compétences

Antonio Bernal Guerrero

Universidad de Sevilla. Departamento de Teoria e Historia de la Educación y Pedagogía Social. Facultad de Ciencias de la Educación. C/. Camilo José Cela, s/n.41018 Sevilla. Correo-e: abernal@us.es

Fecha de recepción: diciembre de 2003

Fecha de aceptación definitiva: marzo de 2004

BIBLID [(1130-3743) 15, 2003, 129-160]

RESUMEN

En este estudio, replanteamos, vinculándolo a su dimensión moral, el problema de la identidad personal. Analizamos los elementos esenciales para la comprensión del fenómeno moral y proponemos el reconocimiento de la identidad en sentido formal, fundamento para el reconocimiento de la identidad de los demás, como alternativa a la tradicional perspectiva sustancializadora y al enfoque posmoderno que propone su 
disolución. Desde esta fundamentación del constructo identidad personal, se plantea la posibilidad de la construcción de la dimensión moral como parte central de la configuración positiva, humanizadora, de la identidad de la persona. Como componente esencial de un proyecto de educación moral, tratamos de delimitar las competencias generales que configuran la identidad moral del sujeto. Desde un enfoque educativo que asume la complejidad y la incertidumbre de los fenómenos humanos, las competencias propuestas se dirigen a la construcción posible de una persona moralmente autónoma.

Palabras clave: identidad, identidad personal, identidad moral, educación moral, competencias educativas, teoría de la educación, sujeto, persona, valores.

\section{SUMMARY}

This study approaches the problem of personal identity linked to its moral dimension. We analyse the elements that are essential for understanding the moral phenomenon and we propose the recognition of identity in a formal sense, the basis for the recognition of the identity of others as an alternative to the traditional substantialising focus and to the post-modern focus that proposes its dissolution. From this basis for the personal identity construct, we propose the possibility of constructing the moral dimension as a central element of the positive, humanising configuration of the individual. As an essential component of a moral education project, we try to define the general responsibilities that configure the subject's moral identity. The proposed responsibilities are directed towards the possible construction of a morally autonomous individual from an educational approach that is fully aware of the unpredictable nature of human phenomena.

Key words: identity, personal identity, moral identity, moral education, educational responsibilities, educational theory, subject, individual, values.

\section{SOMMAIRE}

Dans cette étude, nous posons une fois de plus, en le rattachant à sa dimension morale, le problème de l'identité personnelle. Nous analysons les éléments essentiels en vue de la compréhension du phénomène moral et nous proposons la reconnaissance de l'identité dans son sens formel, comme fondement de la reconnaissance de l'identité des autres, comme alternative au point de vue substancialisateur et d'une optique post-moderne qui propose sa dissolution. À partir du fondement de la constructivité de l'identité personnelle, on envisage la possibilité de la construction de la dimension morale comme partie centrale de la configuration positive, humanisatrice, de l'identité de la personne. Comme compétence essentielle d'un projet d'éducation 
LA CONSTRUCCIÓN DE LA IDENTIDAD PERSONAL COMO PROYECTO DE EDUCACIÓN MORAL. SUPUESTOS TEÓRICOS Y DELIMITACIÓN DE COMPETENCIAS

morale, nous essayons de délimiter les compétences générales qui configurent l'identité morale du sujet. D'un point de vue éducatif qui assume la complexité et l'incertitude des phénomèmes humains, les compétences proposées visent à la construction possible d'une personne moralement autonome.

Mots clef: identité, identité personnelle, identité morale, éducation morale, compétences éducatives, théorie de l'éducation, sujet, personne, valeurs.

La construcción de la identidad personal es un proceso eminentemente dinámico, puesto que en el curso de la vida misma los elementos configuradores de la identidad pueden modificarse. Curiosa y paradójicamente, en todo este proceso se produce un movimiento hacia la segregación, hacia la independencia, hacia la individuación, que resulta básico para llegar a construir la identidad personal; pero, al mismo tiempo, no es posible la individuación del sujeto sin la participación de los otros. Estamos abocados a la configuración de una identidad personal. Ahora bien, la mera construcción de la identidad no asegura su carácter humanizador, verdaderamente emancipador. Esto sólo es posible cuando la construcción de la identidad personal se realiza desde un proyecto educativo, cuando el sujeto se implica en la construcción sociocultural de su personalidad moral. Si preparar para la vida es tarea de la educación, más específicamente de la educación moral, la construcción de la identidad personal se convierte en proyecto de educación moral. Ese producto relativamente autónomo que cada sujeto ha ido construyendo, paulatinamente, a través de sus múltiples interacciones con otros individuos en entornos cada vez más complejos y plurales, a lo que llamamos identidad personal, no deja de interpelarnos y de estimular nuestra imaginación en busca de renovadas propuestas humanizadoras.

1. SuPuestos teóricos. El PROBLEMA DE LA “IDENTIDAD PERSONAL". LA RELACIÓN ENT'RE EL "SER" Y EL "DEBER SER"

Inicialmente, tratamos de analizar el problematismo de dos elementos esenciales para la comprensión del fenómeno moral. Esta problemática constituye un quehacer previo al sentido y alcance de la acción moral, educativa. Primeramente, inquirimos el constructo aidentidad personal"; en segundo lugar, indagamos la relación entre el "ser" y el "deber ser", entre las cuestiones de hecho y de valor. En la medida en que precisamos saber si es posible la construcción con sentido de la identidad personal, para afrontar adecuadamente la acción educativa, hemos de interrogarnos previamente por la consistencia misma de eso que denominamos identidad personal. Al mismo tiempo, la actualización de la noción de sujeto nos inclina a realizar las propuestas pedagógicas morales desde la superación de la vieja dicotomía entre el ser y el deber ser. En este sentido, acometemos la polémica entre éticas teleológicas y éticas deontológicas. El análisis del problema de la identidad 
personal nos acerca al reconocimiento de la identidad en sentido formal, como alternativa a los enfoques tradicional y posmoderno de la cuestión. El conocido debate entre éticas teleológicas y deontológicas requiere nuevas fórmulas superadoras.

\subsection{El constructo “identidad personal. Reorganización de la noción de sujeto}

Para la modernidad, ser sujeto, gozar de identidad personal, implica poseer subjetividad, autopertenecerse de un modo irrenunciable. Tal subjetividad se funda en la capacidad de decidir, de elegir, apoyada en una voluntad libre. El proceso de emancipación y secularización de la modernidad puede entenderse como consecuencia de la evolución histórica y sociocultural de nuestra civilización, que ha posibilitado la liberación del sujeto respecto de una red de proteccionismos por parte de la colectividad que le impedían su autenticidad, la expresión pública de su libertad. La sociedad se ha convertido, pues, en el espacio donde puede o no manifestarse esa libertad, donde puede hacerse o no realmente efectiva ${ }^{1}$. Con la posmodernidad, se ha pasado del reconocimiento del sujeto, de su identidad sustancialista, a su cuestionamiento radical, con una revivificación de las filosofías de la diferencia, que llegan al deconstruccionismo (Derrida, 1994), donde el sujeto queda fragmentado sin posibilidad unificadora alguna. El debate de la posmodernidad acaso haya puesto de relieve la parcialidad e insuficiencia de la tesis moderna, pero tal vez también, de modo consciente o no, de la propia tesis posmoderna. La verdad sobre el problema de la identidad personal nos reclama un esfuerzo de indagación y de síntesis superadora.

Para los modelos behavioristas contemporáneos de la conducta, el sujeto, sencillamente, no existe porque no se ve. En el ámbito estrictamente filosófico el sujeto se entiende como trascendental, fuera de la experiencia, dependiendo del espíritu puro. En ambos casos no se afrontan sus ambivalencias, contradicciones e incertidumbres, su sentido y su levedad, su centralismo y su insuficiencia (Morin, 2001). El regreso de la idea de sujeto, del constructo identidad personal, requiere una reorganización conceptual susceptible de inquirir las ambivalencias y las paradojas que se hallan en el sujeto, una reconceptualización que revele la posibilidad de una construcción con sentido de la identidad personal, capaz de poner de manifiesto que no es imposible que los sujetos se reconozcan en unos determinados relatos identitarios, en unos significantes y significados concretos. Necesitamos pensar la

1. Originariamente, nuestra disposición activa socializada es la que ha permitido procurar independizarnos de las adversidades de la naturaleza y reforzar nuestra dependencia de los vínculos sociales (MACINTYRE, 2001). En este sentido, la creación de normas y pautas de colaboración, de un contrato de protección social mutua, es la primera gran invención libre del hombre. Ahora bien, el devenir del desarrollo político ha consistido desde un punto de vista histórico en la lucha por la ampliación del número de sujetos libres, desde la abolición de la esclavitud a la proclamación de los derechos humanos. 
identidad personal de otra manera, no como esencia individual que conocer, sino más bien como un diálogo entre el individuo y sus otros de referencia.

Progresivamente, se ha ido contrastando la capital importancia del proceso de socialización en el modo de verse y entenderse el sujeto ${ }^{2}$. Ni siquiera las explicaciones causales más intensas de nuestra condición pueden tener sentido si no es desde la intelección del mundo simbólico que constituye la cultura humana (Bruner, 1991). Nuestras actividades biológicas más elementales se hallan ligadas a normas, prohibiciones, símbolos, tabúes, mitos y ritos, esto es, a lo más específicamente cultural de nuestra condición; lo más biológico (nacimiento, muerte, sexo) es a la sazón aquello que más impregnado está de símbolos y de cultura (Morin, 2002). Al mismo tiempo, sabemos que los procesos de enculturación son posibles por las capacidades que nuestro organismo posee. En la interacción con el mundo, con los otros, el sujeto va construyendo su propia identidad, mediante un fenómeno de autoorganización por el cual es capaz de asumir su peculiar enfoque de la realidad, de ubicarse centralmente en su mundo. Este fenómeno autoorganizativo se produce en el complejo contexto de las interacciones entre el individuo y la sociedad ${ }^{3}$. Desde una original dependencia de su contexto cultural, la persona es autónoma, de un

2. Es muy interesante, no obstante, otra perspectiva, abierta a la indagación: la que analiza, digamos, la antesala del sujeto desde el espacio estrictamente interior de la intimidad. El filósofo Peter SLOTERDIJK (2003) afirma que los ámbitos presubjetivos olvidados por el subjetivismo moderno y por el objetivismo científico ya vienen marcados por un ser-con primigenio. Desde una reelaboración libre y original del ser en el mundo heideggeriano, Sloterdijk subraya que interrogarnos por dónde estamos nos lleva a pensar el habitar del hombre como un estar en esferas, espacios de relacionalidad que le van configurando pero que él mismo también configura, espacios que al romperse abren al individuo a nuevos modos de estaren, a nuevas esferas. El espacio interior de la intimidad ("burbujas"), la espacialidad originaria de la existencia antes de ser histórica o temporal, constituye, para Sloterdijk, una suerte de protohistoria de la subjetividad, una especie de antesala del sujeto. Ese espacio interior perdura en el individuo y conforma, antes que el individuo autónomo y soberano (perspectiva moderna), el locus central de la subjetividad. De este modo, las condiciones del sujeto están dadas no tanto por los contextos históricos de significado (como muestran las formas más habituales de hermenéutica o deconstrucción) cuanto por las propias relaciones protopsicológicas.

3. La vida en sociedad requiere que las personas sean en cierto modo fiables, es decir, que se hagan responsables de su conducta y que ésta de alguna manera resulte previsible. En este sentido, la identidad es una garantía de la continuidad de la persona, una garantía para la posibilidad misma de la interacción social. La pérdida de confianza lleva a la exclusión de las relaciones humanas, a la "despersonalización", como señaló WEIGERT (1983). Nuestra identidad posibilita que otras personas sepan a qué atenerse y confien en una reacción adecuada a la interacción. Así, la continuidad de nuestra identidad, la coherencia del yo, es de capital importancia para facilitar las relaciones sociales y su institucionalización misma, como indicaron BERGER y LUCKMANN (1967). La interacción social reclama la confianza de unos en otros para saber a qué atenernos en las interacciones humanas. La identidad personal genera un marco de estabilidad necesario para permitir los contactos sociales con cierta fluidez, lo cual nos permite gozar de ciertos derechos a los que somos acreedores precisamente por ser quienes somos. De no ser así, en cada interacción habría que preguntarse por las demandas de identidad del otro interactuante, hacerle conocedor de las nuestras y tratar de negociar, no sin penosas dificultades, hasta dónde alcanzan los límites de lo que podamos aceptar en esa situación concreta, asumiendo que en cada momento nos encontraríamos ante un desconocido. 
modo relacional y relativo; como dijera Ortega ${ }^{4}$, la vida es el hecho radical y la vida es circunstancia, sin salvar a la circunstancia no se salva uno mismo. Uno de los máximos exponentes de la filosofía hermenéutica europea, Paul Ricoeur (1990), ha señalado que la ipseidad —una de las acepciones de lo idéntico- del "sí-mismom conlleva la alteridad en un grado tan elevado que uno no se deja pensar sin el otro5.

El conjunto de instituciones humanas que denominamos cultura es fundamental para el desarrollo y liberación del sujeto racional. Sin duda, la cultura es producto de la disposición inteligentemente activa del ser humano, pero a la vez ha favorecido el incremento de la capacidad cerebral del hombre para elegir e inventar. Los actuales seres humanos no somos el mero resultado de la evolución biológica sino la propia obra de la capacidad práctica de actuación de nuestros antepasados. En este sentido, podríamos decir, con Savater (2003, 92), que el hecho de ser racionalmente activos, fundamento de la libertad, de los fenómenos de libertad ${ }^{6}$ que somos capaces de experimentar, ano sólo nos define sino que también ha contribuido

4. Afirma ORTEga y Gasset: "Yo soy yo y mi circunstancia, y si no la salvo a ella, no me salvo yo" (Meditaciones del Quijote, Obras Completas, tomo 1, p. 322). Aclara Ortega que uno ha de comprenderse a sí mismo como una unidad inseparable del cúmulo de circunstancias que le rodean, con aquello que puede denominarse "mi mundo". No soy yo y el mundo, sino que tanto el mundo como el yo constituyen una unidad constitutiva de mi vida. Por lo demás, puede advertirse que la perspectiva del yo circunstanciado orteguiano presenta ciertas connotaciones comprensivas para la moral. En la perspectiva kantiana la vida ética exige el reconocimiento de los otros como seres dignos y libres; el proyecto de cada persona, de cada sujeto racional, no puede impedir los proyectos de otras personas, antes al contrario, la bondad moral está en respetar y facilitar todo lo posible los proyectos de los otros, que nunca pueden ser tratados como medios sino como fines en sí mismos. En Ortega, no únicamente se considera la existencia de los otros como iguales a nosotros, sino que además se integra a los otros en el sujeto como su propia circunstancia.

5. En su obra Soi-même comme un autre, Paul Ricoeur se aleja del cogito cartesiano en la medida en que Descartes señalaba como punto de partida el sujeto como yo y como yo pensante. Nos indica Ricoeur que en la narración se supera la primera persona y se toma como sujeto el conjunto de personas gramaticales, aunque se use la tercera persona de manera privilegiada; de aquí se infiere que el autor emplee el término soi para referirse a la capacidad reflexiva de todos los sujetos. Tal mediación reflexiva sobre la posición del sujeto halla un notable apoyo en la gramática de las lenguas naturales al distinguir el soi (sí-mismo) del je (yo). Ricoeur formula las dos significaciones fundamentales de la identidad: la del Ídem (lo mismo, mismidad) y la del ipse (uno mismo, ipseidad). La equivocidad del término idéntico se encuentra inmersa en el análisis de la identidad personal y de la identidad narrativa, en relación con la temporalidad como rasgo dominante del "sí-mismon; el tiempo es tiempo humano porque está articulado de manera narrativa, la identidad del "yo" se relaciona con la capacidad de poder seguir una narración. Ricoeur plantea una dialéctica entre el "Sí-mismo" (soi) y el "otro" (autre que soi). Precisamente, "Soi-même comme un autre" hace referencia a que la ipseidad del "Sí-mismo" implica la alteridad de un modo tan intimo que uno no se piensa sin el otro; no se trata de una mera comparación, uno mismo parecido a otro, sino de una implicación: uno mismo en tanto que otro. La acción es acción con otros, de manera que el problema del otro está implicado en la narración.

6. Los fenómenos de libertad que el sujeto experimenta nos aparecen bajo el signo de una plural y no unitaria familia. Desde una perspectiva empírica, tanto una visión determinista como la postulación de un ser humano radicalmente libre no parecen sostenerse (FIERro, 2002). Más bien se puede hablar de una atribución o predicación de libertad, de distintos modos de conducta libre, según medida o grados. De la persona y de su acción puede predicarse el atributo de libre, pero más que por una 
LA CONSTRUCCIÓN DE LA IDENTIDAD PERSONAL COMO PROYECTO DE EDUCACIÓN MORAL. SUPUESTOS TEÓRICOS Y DELIMITACIÓN DE COMPETENCIAS

decisivamente a configurarnos como especie”. La acción del hombre no sólo está vinculada al despliegue de conductas instintivas, sino que también lo está, significativamente, al registro simbólico de posibilidades de acción que abren su conducta a lo inédito, a lo nuevo, a lo desconocido, más allá de los patrones de comportamiento establecidos en el pasado por los miembros de su especie. Gracias a nuestro cerebro, específico órgano de la acción, conocemos, deliberamos, evaluamos y decidimos; o sea, merced al cerebro humano tenemos moralidad ${ }^{7}$. No sólo heredamos, pues, la carga genética, también recibimos el legado cultural de nuestros antepasados; pero si aquélla se nos concede gratuitamente, las adquisiciones culturales hemos de aprenderlas con nuestro esfuerzo. En este sentido, puede afirmarse, con Aristóteles ${ }^{8}$, que la acción (praxis) es creadora de humanidad. Es la condición activa (incluso estar pasivamente en el mundo implica una elección, una actuación en términos generales) del hombre la que ha propiciado el principio, el inicio, de lo que específicamente le define.

La reorganización de la idea de identidad personal nos urge si nos preocupa la intelección de su realidad, particularmente para su consideración como agente de conducta (Bernal, 2002). Los distintos sistemas biológicos, neuronales, conductuales y conscientes de un individuo constituyen un todo, una totalidad, que trata de articular la unidualidad cuerpo y psique. Esta totalidad consiste en una realidad polisistémica, integradora e integrada de sistemas distintos. Precisamente la complejidad interna y la multiplicidad de subsistemas integradores del "yo" ponen en riesgo la unidad del sujeto. Una tríada interior a la persona, delimitada por tres clases de instancias y de procesos de sujeto (afectivos y emotivos, cognitivos y de pensamientos, de acción propiamente dicha), nos refiere a una pluralidad de "sujetos", dentro del mismo sujeto personal, de los que no se puede asegurar que coincidan perfectamente. Alfredo Fierro (2002, 274) lo expresa así:

El sujeto aparece compuesto, en realidad, por varios subsistemas comportamentales. Los elementos que lo componen no son idénticos entre sí, ni tampoco están perfectamente integrados, mucho menos jerarquizados. Su principal —por no decir única- organización es de cara al exterior: en efecto, la persona funciona como una unidad en sus relaciones de intercambio adaptativo con el mundo. Ciertamente ésta es la unidad funcionalmente necesaria y suficiente: basta con ella. En sus procesos internos, en cambio, no funciona ya de manera global e indistinguible.

determinada cualidad ontológica interna y unitaria, por un haz de cualidades empíricas no ordenadas con una absoluta perfección.

7. Dice John RATEY, profesor de psiquiatría de la Universidad de Harvard: “Para empezar, lo menos que podemos hacer es enterarnos de qué se sabe ahora acerca de cómo nuestros cerebros hacen lo que hacen. En contra de la creencia popular, ése es un propósito no sólo científico, sino también moral: el conocimiento de uno mismo hace que sea aún más nuestra la responsabilidad de llevar una vida que maximice los puntos fuertes que podamos tener y minimice nuestras debilidades" $(2003,23)$.

8. Cfr. Ética a Nicómaco, Lib. VI, cap. X. 
El conocimiento de la persona por dentro requiere, pues, desmenuzarla en su innegable pluralidad.

El sujeto consiste en un sistema de comportamientos, o en una red de fenómenos, es decir, en una realidad que presenta en cierta medida estructura y organización. Mejor dicho, más que un sistema de comportamientos, se trata de diferentes sistemas o subsistemas de comportamientos. Esto significa adoptar un nuevo enfoque sobre la unidad y la identidad del sujeto. En el pensamiento occidental -en otras culturas no ocurre lo mismo (Rabinow y Sullivan, 1979)- existe una luenga tradición por que se considera a la persona como una entidad motivacional y cognitiva bien entrelazada y altamente unificada 9 . Sin embargo, el personoanálisis (Greenwald, 1980; Gordon y Gergen, 1986) ha propugnado que el sujeto, más que una realidad sola e indivisa, consiste en muchas realidades, muchos sucesos o propiedades reales de la conducta, de la acción. La persona se halla configurada por diversos sistemas — verbal, corporal, del si mismo y social-, separados, y, a menudo, en claro conflicto. En una palabra, para la teoría personoanalítica, el sujeto queda configurado por una multiplicidad de fenómenos y procesos que no guardan unidad entre sí. Realmente, en la configuración de la persona intervienen múltiples procesos de los que no conocemos su integración empírica, desde aquellos que definen la individualidad psicológica y el carácter activo del sujeto hasta los que coadyuvan a la representación social del sujeto, pasando por los relacionados con la adaptación y el propio desarrollo del individuo.

En un arco que abarca fenómenos que se extienden desde la autorreferencia a la exorreferencia se perfila la identidad del sujeto (Westen, 1985). Si se repara con atención en la propia realidad del sujeto personal, es fácil observar que su identidad describe trayectorias que comprenden desde la distinción o exclusión, por la que cada "yo" es único, hasta la inclusión o reunificación, por la cual podemos incluir el "yo" en un "nosotros" o un "nosotros" en nuestro "yo" (Morin, 2001). Se hace necesario el reconocimiento de complejidad de la continuidad. Hay un continuo entre la capacidad de referirse a uno mismo y la capacidad de referirse al mundo exterior, especialmente a los otros (heterorreferencia). Las acciones humanas discurren desde el interior del sujeto hasta el mundo exterior en un continuo altamente complejo.

Un vínculo entre el sistema de "sí mismo" y el mundo exterior (exorreferencia) podemos hallarlo en el repertorio de comportamientos defensivos, de autoprotección física y psíquica y de afrontamiento de peligros y amenazas de distinto tipo. Este conjunto de conductas se dirige a la supervivencia del sujeto y a su

9. Las teorías personalistas se distinguen por mantener la tesis de la identidad de la persona en la radical coincidencia y unidad de los diferentes conjuntos de fenómenos y procesos de personalidad (Allport, 1988; MAslow, 1962 ...). Para las teorías personológicas, todos los fenómenos de personalidad constituyen manifestaciones de un idéntico principio sustancial, unitario e indiviso, estructural y de carácter dinámico. 
LA CONSTRUCCIÓN DE LA IDENTIDAD PERSONAL COMO PROYECTO DE EDUCACIÓN MORAL. SUPUESTOS TEÓRICOS Y DELIMITACIÓN DE COMPETENCIAS

optimización ${ }^{10}$ constituyendo un sistema caracterizado por los recursos de protección y afrontamiento del sujeto. Ahora bien, un enlace, un nudo, un vínculo plausible entre el sistema de autorreferencia y el de heterorreferencia puede encontrarse en el momento de la autopresentación. La presentación de uno mismo ofrece un paradigma de comunicación e interacción social. La presentación del propio sujeto es una acción orientada por completo al exterior, hacia otros sujetos, y sin embargo sigue siendo conducta autorreferida porque el objeto y el contenido de la comunicación sigue siendo uno mismo: "Por un lado, parece alojarse en la autoconciencia y desprenderse de ella; por otro, es pura exterioridad, fachada y escaparate, mera colección de máscaras, de roles» (Fierro, 2002, 284). Desde luego, podemos pensar que nada hay previamente a la presentación de sí y, si en algún caso se llega a crear algo que pudiéramos denominar "sí mismo", quedaría configurado por la progresiva acumulación de las sucesivas presentaciones y representaciones que el sujeto realiza. No obstante, también es posible realizar una interpretación distinta y opuesta: la presentación de sí se realiza en el sistema de sí mismo, es una actividad en última instancia autorreferida y la serie de personajes que presentamos en los diferentes escenarios sociales es en realidad el producto de una actividad de presentación de sí mismo. No es en exceso aventurado suponer que el sujeto autoconsciente no es el mismo sujeto exactamente que se presenta en sociedad, ni se identifica enteramente con aquel sujeto activado y dispuesto internamente para la acción en un determinado sentido. Por otra parte, el "yo" es una totalidad que está constituida no únicamente por los sistemas conscientes de un individuo, sino igualmente por sus sistemas biológicos, neuronales y comportamentales en sentido amplio. El "yo" es una realidad compleja y polisistémica.

Pese a todos los cambios que sufrimos a lo largo de la vida parece permanecer esa capacidad de autorreferencia por que decimos "yo" para referirnos a algo que nadie más puede hacer, que nadie puede invocar en nombre de nadie. Este yo es quien percibe, recuerda, se emociona, anda, corre, se alimenta, disfruta, afronta la realidad y aun la transforma, emplea el lenguaje y es capaz de comunicarse con otros, aunque se trata evidentemente de un yo imperfectamente unificado y acaso no jerarquizado. La capacidad de verse y pensarse a uno mismo como sujeto entre otros sujetos se halla íntimamente vinculada a un sentimiento de continuidad biográfica, en el espacio y en el tiempo. La memoria nos permite mantener la identidad personal. Toda la información experiencial no puede ser almacenada por nuestra mente, hay olvido. Sólo recordamos selectivamente y no siempre con precisión. Así, mediante la transformación de ese caudal informativo en narraciones sobre uno mismo, a través de las versiones que construimos acerca de la realidad y sobre nosotros - validadas por los demás, o sea, aceptadas por las demandas implícitas de identidad-, conformadas a través de nuestras percepciones, nuestros

10. Este espacio del sujeto se halla especialmente vinculado a los efectos de la represión social, espacio frágil y fronterizo, cuando no rayano, con lo patológico (FiERro, 2002). 
sentimientos, nuestros pensamientos, nuestras acciones, nuestro discurso, se va configurando nuestra autobiografía consciente (Habermas, 1988), nuestra identidad personal. La memoria impide la disolución absoluta de la identidad, la terrible condena a la construcción continua de un mundo y de un "yo" diferentes a cada momento (Sacks, 1985). El sujeto memoriado precisa esa narración, continua, único modo de conservar su identidad. Es la memoria, finalmente, construida con materiales de la propia experiencia y de la que incorpora de la colectiva, la que nos sujeta a nuestra biografía, a nuestra historia, a nuestra identidad. La noción de identidad personal hace sentido para representar esa realidad fenoménica por la cual el individuo unifica, reunifica, la diversidad de potencialidades, caracteres y personajes que moran en cada ser humano. Podemos reconocer, pues, un espacio para la conciencia personal a modo de polo de capacidad dinámica, susceptible de tener intenciones, fabricar proyectos y conservar una cierta identidad en el tiempo.

\section{2. Éticas teleológicas y éticas deontológicas}

Las concepciones teleológicas de la moralidad no se refieren a obligaciones o prescripciones sino a fines, a programas, a valoraciones de las conductas por sus consecuencias. Las éticas no deónticas se ocupan de la buena vida, de la vida apetecible, de la vida feliz, de la recta práctica, del hombre justo, de la acción placentera o dichosa, de aquella que merece aprobación o rechazo. Las éticas no deontológicas se ocupan de problemas morales relativos al mejor modo de encontrar la felicidad (bien) y evitar el dolor y el mal. O sea, las éticas teleológicas son consecuencialistas, les importa, para considerar si una norma es correcta o no, tener en cuenta las consecuencias que se seguirían de su puesta en acción. Según la tradición kantiana, una ética deontológica sería no consecuencialista, considera que para afirmar si una norma de acción es correcta o no hay que atender a la bondad o maldad de la norma en sí misma.

La polémica entre éticas teleológicas y éticas deontológicas puede apreciarse en cierto modo en el problema de la "falacia naturalista". Desde Hume o Kant, la filosofía moderna ha enunciado la imposibilidad lógica de pasar del "ser" al "deber ser. La Crítica de la razón práctica kantiana aunque termina estableciendo un imperativo categórico, un "deber ser" (un sollen), éste no es reductible en modo alguno al ámbito de los fenómenos. La concepción kantiana de lo moral es en sentido estricto deontológica; en ella se considera virtuosa la acción humana que se realiza por acatamiento de lo prescriptivo, de la obligación por ser precisamente obligación, sin considerar ni la inclinación personal ni las consecuencias de dicha acción. Obviamente, hay aquí una clara identificación entre el deber y la moral. La ética de los valores (Scheler, 1941; Hartmann, 1954) pretendió contrarrestar el formalismo kantiano - la ética formal del imperativo puro- mostrándose como ética de contenidos o material, pero en verdad terminó siendo un complemento del "deber ser" kantiano, ya que éste no se abandona en realidad sino que se completa 
LA CONSTRUCCIÓN DE LA IDENTIDAD PERSONAL COMO PROYECTO DE EDUCACIÓN MORAL. SUPUESTOS TEÓRICOS Y DELIMITACIÓN DE COMPETENCIAS

con la materialidad de contenidos valorales, con una teoría y jerarquía de los valores (axiología). Como resultado, la ética de los valores presenta una escisión radical entre los hechos y los valores; el "deber ser" no pertenece al "ser" y no hay paso de éste a aquél. Los valores no pertenecen al dominio de lo factual y no hay tránsito de los hechos y de los juicios de hecho a los valores y a los juicios de valor. Ser y deber ser, hecho y valor, constituyen así una dicotomía de imposible superación lógica o epistemológica. Cualquier intento de rebasar esta fracción ha sido tachado de "falacia naturalista " ${ }^{11}$. El tránsito indebido del lenguaje descriptivo al lenguaje evaluativo ha sido puesto de manifiesto y argumentado vigorosamente por la moderna filosofía del lenguaje en su aplicación a los enunciados morales. En efecto, si se acata la anterior división tajante entre hecho y valor, resulta muy difícil combatir la tesis de la "falacia naturalista". En el ámbito de las ciencias sociales, es muy célebre el intento de superación de tal "falacia" por parte de Lawrence Kohlberg (1981), quien partiendo de un explícito reconocimiento de la perspectiva kantiana ha tratado de comprobar empíricamente la evolución universal del razonamiento moral en el sujeto consistente en el paso desde el "ser" hasta el "deber ser. Los diversos niveles morales (preconvencional, convencional y posconvencional), con sus respectivos estadios, hacen referencia al tipo de razonamiento que los individuos desarrollan acerca de las cuestiones, decisiones y normas morales. Según Kohlberg, una vez adquirido el pleno desarrollo cognitivo y moral, el sujeto asume necesariamente imperativos universalmente válidos, más allá de personas y contextos, por encima de acuerdos sociales. No se trata de que la sola evolución ontogenética fundamente por sí misma el modo prescriptivo de la moralidad, aunque Kohlberg cree que los principios éticos suponen la culminación "natural" del proceso evolutivo del individuo. Para él, los mecanismos que determinan esa secuencia evolutiva son preponderantemente sociales; es la experiencia de las relaciones humanas, de la interacción social, la que termina por impulsar y orientar el desarrollo moral. De esta forma, los patrones de moralidad se entienden como construcciones que realizan los individuos para ordenar sus interacciones.

Efectivamente, quizás la distinción entre hecho y valor, entre ser y deber no sea tan radical como tradicionalmente hemos pensado. Las cuestiones de valor no se identifican rigurosamente con las cuestiones de hecho, pero eso no significa que sean absolutamente independientes entre sí. La absoluta escisión entre el

11. La denominada "falacia naturalista" consiste en derivar conclusiones expresadas en un lenguaje evaluativo (de los juicios de valor, de las normas), como el de la moral, a partir de premisas expresadas en un lenguaje descriptivo, como el de la ciencia. Como es sabido, el análisis sistemático del lenguaje moral fue iniciado a principios del siglo xx por el filósofo inglés George Edward MoORE (1962) con su obra Principia Etbica, de 1903. Para Moore, el significado del adjetivo bueno es un pseudo-problema, es indefinible porque no tiene ningún referente y además por ser una cualidad simple (sólo son definibles los conceptos complejos) no puede descomponerse. Cualquier empeño en querer definirlo sigue el paso del ser al deber ser, lo que Moore denominó "falacia naturalistan, entendiendo que los predicados morales son predicados específicos de la moralidad, irreductibles, por consiguiente, a cualesquiera predicados naturales. 

SUPUESTOS TEÓRICOS Y DELIMITACIÓN DE COMPETENCIAS

hecho y el valor ha de ser cuestionada. Creer que son dos esferas esencialmente divididas no permite posteriormente ningún género de enlace ni lógico ni epistemológico, pero es que además posiblemente no sea cierta tal tajante partición. Una ontología que trate de mostrar que el deber es una forma del ser procura soslayar esa división: “...es necesario darse cuenta primero de que las cosas que existen son a menudo incompletas. Parte de su realidad está todavía en el orden de la potencialidad" (Grisez y Shaw, 1993, 91). Por esta misma vía filosófica, los valores si son algo son también realidades, aunque se trate de realidades singulares. Obviamente, la discusión puede seguir por esta vía filosófica. Al fin y al cabo, el sentido del valor radica en su efectiva posibilidad de realización. Pero podemos analizar el problema de otro modo, desde el reconocimiento de complejidad de la continuidad entre el ser y el deber ser, sin incluir necesariamente el deber ser en el ser. En realidad, hecho y valor parecen contraponerse bajo el modo de la continuidad. Contenido fáctico y contenido valorativo parecen configurar el ámbito de la verdad histórica, de modo que la distinción entre el es y el debe pertenece más bien al área de la reflexión y de la abstracción que al de la vida misma (López Aranguren, 1976; Apel, 1986). Las éticas deontológicas actuales, por ejemplo, son consecuencialistas, esto es, consideran el deber ser y las consecuencias que de su práctica se derivan en la realidad: la ética del discurso (Apel, 1986, 1990; Habermas, 1985) y la justicia como equidad (Rawls, 1978). La ética discursiva de Apel ha terminado por no sostener la separación entre ética deontológica y ética teleológica ${ }^{12}$. Hecho y valor constituyen elementos opuestos de un mismo segmento, no son esferas radicalmente separadas. Los diversos niveles reguladores o prescriptivos de la conducta de los individuos conforman en realidad un continuo que abarca desde las normas más simples de cortesía hasta los más altos principios éticos formales («no desees para otro lo que no deseas para ti", "no hagas a los otros lo que no quieres que te hagan a tin) y materiales ("no mientas", "no robes", "no mates"...), pasando por normas sociales aprobadas por la comunidad o por normas jurídicas. Estas normas no coinciden

12. La ética discursiva de Apel se comprende como una ética de la responsabilidad y no como una ética de la convicción - siguiendo la clásica distinción efectuada por Max WEBER (1980), quien contrapuso la ética de la responsabilidad a las éticas de la convicción que se orientan por principios y valores, sin una conveniente consideración de las consecuencias de la acción-. En la ética discursiva la aplicación del principio de responsabilidad debe estar regulada por el principio del discurso. El principio de complementariedad moral-estratégico de la ética de la responsabilidad planteado por APEL (1990) viene a ser un principio teleológico orientado al afrontamiento de las adversidades para que puedan darse verdaderos diálogos, o sea, un principio dirigido a la realización de las condiciones del discurso moral (de simetría, no violencia, no exclusión...). Presentado así el principio de la responsabilidad, no cabe mantener la separación entre ética teleológica y ética deontológica. Las personas son individuos comunitarios según la ética del discurso, personas dialógicas; por esta razón, la ética del discurso considera que la prueba para comprobar si una norma es moral es dialógica, porque la racionalidad humana es dialógica. Pero esta consideración no cierra el debate: ¿Realmente podemos considerar que la racionalidad humana no es también monológica?, ¿no puede un sujeto autónomo realizar el test del imperativo categórico?, ¿se trata de un proceso exclusivamente racional?, ¿cuál es el fundamento último de una ética de la responsabilidad: trascendente y absoluto o relativo y discutible? (RAwLs, 1978; TugENDHAT, 1997). 
LA CONSTRUCCIÓN DE LA IDENTIDAD PERSONAL COMO PROYECTO DE EDUCACIÓN MORAL. SUPUESTOS TEÓRICOS Y DELIMITACIÓN DE COMPETENCIAS

entre sí pero sí hay contigüidad entre ellas ${ }^{13}$. La regulación de los comportamientos humanos constituye un complejo haz de normas que abarca desde las reglas indispensables para la convivencia cotidiana hasta los más elevados imperativos morales, sin que podamos concentrar tal variedad y complejidad de manifestaciones en dos supuestamente divididas sustancias, en dos polos opuestos y completamente escindidos: ser/deber ser, hecho/valor. La clásica distinción entre éticas consecuencialistas y no consecuencialistas se difumina a la luz de las actuales éticas deontológicas, que son consecuencialistas.

\section{Delimitación DE COMPETENCIAS}

Todo proyecto de educación moral comprende diversos elementos: contenidos relativos a hechos y conceptos, a procedimientos y a valores, actitudes y normas; actividades y recursos metodológicos y materiales; criterios y procedimientos de evaluación. Pero indudablemente a estos elementos del proyecto habrá que añadir la orientación que se da al mismo. Con un sentido sintético y sin ánimo de concreción a ningún ámbito específico o nivel particular de la educación, procuramos establecer aquellas competencias generales que puedan guiar un proyecto de educación moral autónoma, apuntando hacia la maximización de las oportunidades de emancipación personal, mediante el uso de todos los recursos disponibles del sujeto. Las competencias que proponemos, pues, tienen una indudable referencia a los procesos de enseñanza-aprendizaje más convencionales, pero no se limita a ellos porque pensamos que la construcción de la identidad es, al fin y al cabo, el objetivo de todo el proceso formativo (García Carrasco y García del Dujo, 2001).

Desde el enfoque de las competencias en educación, se ha reclamado la necesidad de vincularlas a las dimensiones afectiva, moral y ética de la persona (Pérez, Cánovas y Gervilla, 1999), lo cual no hace sino ensanchar las virtualidades pedagógicas del enfoque de la formación en competencias. Posiblemente como consecuencia de su origen en el ámbito laboral, el concepto de competencia presenta el riesgo de considerarse desde una dimensión exclusivamente operacional (Schön, 1987), poniéndose énfasis en las operaciones, el entrenamiento, el desempeño y el incremento de las fuerzas productivas, restándose importancia a la comprensión, a la intencionalidad de la persona. Evidentemente, la competencia incluye una dimensión operacional, pero no se limita a ella, sino que también se refiere al punto de vista de la comprensión de las situaciones que los sujetos deben afrontar y de los escenarios problemáticos en los que actúan. En este sentido, la competencia presupone otorgar un claro valor a la intencionalidad del sujeto, en tanto

13. Dentro de las variedades propias del lenguaje cotidiano, éste también parece articularse en un continuo. El paso desde el indicativo hasta las formas evaluativas, exhortativas, imperativas, se realiza gradualmente. Se dice al niño: "No te hurgues en la nariz". A continuación: "¿Quieres hacer el favor de no hurgarte en la nariz?". Después: "Deja de hurgarte en la nariz ahora mismo". 
LA CONSTRUCCIÓN DE LA IDENTIDAD PERSONAL COMO PROYECTO DE EDUCACIÓN MORAL. SUPUESTOS TEÓRICOS Y DELIMITACIÓN DE COMPETENCIAS

que gracias a las posibilidades del carácter de agente que tiene el sujeto es posible organizar las competencias como elementos valiosos y relativamente estables para la dinámica comportamental del sujeto. Las competencias, por tanto, podemos observarlas inferencialmente y no de un modo directo como sucede con las operaciones externas. Las competencias, si bien pueden ponerse de manifiesto puntualmente a través de la ejecución de tareas concretas, poseen un carácter relacional por el que vinculan determinadas notas de la personalidad del sujeto a ciertas tareas o grupos de tareas. Este carácter relacional de las competencias facilita su conexión con distintas tareas haciendo posible su consolidación y enriquecimiento. Las competencias están relacionadas con la puesta en práctica integrada de aptitudes y rasgos de personalidad y con los conocimientos adquiridos. Las competencias no son aptitudes, aunque éstas son imprescindibles para que se desarrollen; no son puros conocimientos que puedan aplicarse a una tarea específica, porque en las competencias también se incluye una experiencia y un dominio real de dicha tarea; los rasgos de personalidad presentan un vínculo con las competencias, pero éstas son unas características diferentes del sujeto, producto de la experiencia y de saberes articulados y automatizados de algún modo. Las competencias tienen un componente de generalidad basado en su vínculo con la personalidad del sujeto:

$\mathrm{El}$ anclaje personal de las competencias, y por lo tanto su carácter general, resulta compatible con su manifestación focal a través del dominio de tareas frecuentemente muy específicas. Quiere esto decir que las competencias son básicamente holísticas, aunque se puedan proyectar de forma puntual (Vázquez, 2002, 68).

El sujeto asimila —y desarrolla a lo largo de su vida- las competencias y, posteriormente, se proyectan en su conducta. Las competencias de la persona "pueden considerarse una categoría específica de notas o características individuales" (Bernal, 2003, 246), sometida a los procesos educativos diferenciados y diferenciadores que inciden en el sujeto y a los procesos de desarrollo que lo modulan singularmente. En resumen, las competencias pueden concebirse como acciones intencionales y se refieren no únicamente a las tareas o habilidades que se ejecutan, sino también a la comprensión de las situaciones problemáticas que los sujetos han de afrontar; por otra parte, aunque las competencias pueden manifestarse focalmente en la ejecución de ciertas tareas específicas, presentan un carácter general fundado en su relación con la personalidad del sujeto. La idea de competencia como categoría específica de notas individuales del sujeto engloba una noción de competencia centrada en los conocimientos y habilidades requeridos para la adaptación eficaz en contextos y tareas más o menos complejos, y comprende, además, de una manera relevante dado el componente de generalidad que implica, la concepción de la competencia como capacidad para una adaptación efectiva -que bien entendida también implica llegado el caso desadaptación, modos varios de transgresión, o sea, se trata de una idea de adaptación relacional, de interacción con el medio, imprescindible para el desarrollo humano, no de conformación, una fórmula más 
LA CONSTRUCCIÓN DE LA IDENTIDAD PERSONAL COMO PROYECTO DE EDUCACIÓN MORAL. SUPUESTOS TEÓRICOS Y DELIMITACIÓN DE COMPETENCIAS

o menos explícita de adoctrinamiento-. En la medida en que las competencias representan un vínculo entre los rasgos o notas individuales y determinados comportamientos, podemos identificar distintos rasgos indicadores de las competencias. Ese entramado de rasgos constituiría una especie de "yo competente", encargado de la organización y mediación de conductas a través de un amplio repertorio de tareas y de roles, configurador de la identidad personal. La educación moral precisamente se puede vincular al núcleo de ese yo competente, y deviene en determinante de competencia generalizada del sujeto. Por supuesto, no es el único determinante de las múltiples competencias específicas del sujeto; pero implica un potencial muy notable para elevar las competencias de la persona, debido al alto poder de adaptación que encierran los rasgos definitorios de ese yo competente, presentando un carácter difusor y transformador de las competencias.

Nuestra propuesta pedagógica para la persona se centra en un conjunto ${ }^{14}$ de competencias, compuesto de cinco categorías que cubren a su vez otras competencias de menor generalidad, girando en torno a la preocupación nuclear por la construcción de la identidad del sujeto desde una perspectiva plenamente educativa $^{15}$, esto es, moral, humanizadora. La propuesta que realizamos quedaría configurada por las siguientes categorías: 1) Poseer sentido crítico; 2) tener criterio propio; 3) presentar sensibilidad emocional; 4) manifestar prosocialidad; 5) mostrar sentido creativo en el ámbito de los valores. A través de estas competencias generales para la educación moral de la persona, se desarrolla a su vez un complejo entramado de capacidades, que abarca desde el desarrollo del juicio moral a la elaboración efectiva de las propias trayectorias de vida, pasando, entre otras, por el desarrollo de la autorregulación y del control y gestión de las emociones. A continuación tratamos de justificar nuestra propuesta.

\subsection{Poseer sentido crítico}

Hoy resulta más necesaria que nunca la formación de un sentido crítico, o sea, el despliegue de elementos que coadyuvan al crecimiento autónomo de la persona para que en el transcurso de su vida sea cada vez más ella misma. Desarrollar el sentido crítico es avanzar en pensamiento autónomo haciendo uso del juicio razonado,

14. En un reciente trabajo, SARRAmona (2003) ha señalado el carácter complejo y holístico de las "Competencias básicas", necesarias para participar a lo largo de la vida en múltiples contextos. Indica, asimismo, cómo para el proyecto DeSeCo las competencias se pueden agrupar en tres categorías: actuar de manera autónoma, emplear los recursos de manera interactiva y actuar en grupos socialmente heterogéneos. Se desprende de estas proposiciones la conveniencia de agrupar las competencias por "Constelaciones".

15. No debemos olvidar que las competencias conforman una especie de estructura imbricada en la persona. Todas las competencias tienen su raíz igualmente en el sujeto y pueden interaccionar entre sí, en la medida en que pertenecen a un mismo entramado de complejidad. Al tratar de definir competencias en el ámbito moral resulta inevitable la referencia a otros ámbitos de la persona. 
LA CONSTRUCCIÓN DE LA IDENTIDAD PERSONAL COMO PROYECTO DE EDUCACIÓN MORAL. SUPUESTOS TEÓRICOS Y DELIMITACIÓN DE COMPETENCIAS

dejando a un lado todas las presiones ambientales de carácter sociocultural. La crítica, que entendida correctamente siempre es positiva, trata de discernir, distinguir, aquello que es valioso de lo que no lo es. El despliegue de las potencialidades críticas del sujeto depende de la calidad de las interacciones que mantiene con el medio cultural. Es decir, depende de la cultura que se le presenta al sujeto y de cómo se le ofrece; es fundamental disponer de principios organizativos que posibiliten la integración de los saberes dándoles un sentido. La persona crítica debe poseer una "cabeza bien organizada", más que llena, "bien hecha", capaz de plantear los diversos problemas de la realidad con vocación de generalidad y de concreción, de globalización y de contextualización. Poseer sentido crítico, esforzarse en pensar bien, significa luchar contra el error y la mentira hacia uno mismo. El sujeto crítico busca en su deliberación la verdad posible, por eso procura fundamentar y argumentar correctamente sus propios juicios, sabiendo que "conocer y pensar no es llegar a una verdad absolutamente cierta, sino que es dialogar con la incertidumbre (Morin, 2001, 76). Ni escéptica, ni dogmática, la persona crítica da razón de su pensar y de su vivir, actuando conforme a sí misma, a su propio carácter o modo de ser personal. La racionalidad crítica y autocrítica nos hace inmunes contra el error.

Para poder poseer sentido crítico, es necesario conocer toda la información que sea relevante para la formación moral de la persona. Ciertas teorizaciones filosóficas, nociones de valor o morales, son imprescindibles para conseguir un conocimiento elemental y satisfactorio. Asimismo, todos aquellos documentos de relieve ético (la Declaración Universal de los Derechos Humanos y la correspondiente legislación sobre los mismos es una documentación clave ${ }^{16}$ y los elementos de raigambre moral de las legislaciones principales por las que se rige la comunidad constituyen elementos valiosos para la formación moral. El sentido crítico no puede construirse adecuadamente sin el conocimiento reflexivo de determinados hechos personales o sociales que se hallan en controversia desde el punto de vista de los valores y que reclaman ejercicios prácticos de juicio, de comprensión y de transformación. Es preciso reflexionar moralmente sobre situaciones concretas plenamente contextualizadas, reconociéndose así las razones empleadas en cada situación particular por los sujetos en ella implicados.

Por otra parte, la persona precisa desarrollar su capacidad de deliberación ${ }^{17}$. Desarrollar el juicio moral permite afrontar de un modo justo los dilemas de valor. El desarrollo de la capacidad de razonar sobre los problemas morales, sobre

16. El análisis de los derechos humanos, como marco y horizonte de una educación en valores, es un requisito imprescindible de la actual educación moral. El ser humano es miembro de una comunidad educativa universal (MEDINA RuBio, 2002).

17. La investigación pedagógica sobre educación moral ha posibilitado el diseño de programas de desarrollo moral en los sujetos centrados en la aplicación de dilemas morales. Pero también hay estudios que han pretendido demostrar que el desarrollo de la reflexividad, como estilo cognitivo, consigue incrementar asimismo el desarrollo moral (GARGallo y GarCía LópEZ, 1996). 
LA CONSTRUCCIÓN DE LA IDENTIDAD PERSONAL COMO PROYECTO DE EDUCACIÓN MORAL SUPUESTOS TEÓRICOS Y DELIMITACIÓN DE COMPETENCIAS

aquello que se considera correcto, se halla estrechamente vinculado a los principios desde los que se efectúa cada juicio. Las exigencias criteriales del juicio moral nos impelen a la búsqueda incesante de argumentaciones morales justas mediante el debate y la discusión, más allá de todas las presiones de cualquier signo. Íntimamente ligado al logro de criterios de juicio moral se encuentra el desarrollo de aquellas habilidades que posibilitan contrastar de un modo crítico los distintos enfoques sobre la realidad. La comprensión crítica de la realidad no sólo requiere el desarrollo de habilidades que permitan adquirir información moralmente significativa, sino que el sujeto alcance habilidades dialógicas que le permitan establecer intercambios de ideas y de opiniones, así como la posibilidad de razonar sobre el punto de vista del interlocutor o interlocutores tratando de llegar realmente a un entendimiento, lo que supone incluso el cambio de opinión propia si así resulta pertinente. El diálogo debe presentar un uso recurrente en las situaciones educativas de cualquier género. No en vano el diálogo en sí mismo podríamos considerarlo un valor fundamental para la propia educación moral y para la vida democrática. El diálogo se halla en la raíz misma de la conciencia moral autónoma.

\subsection{Tener criterio propio}

Pensar por sí mismo y de un modo correcto implica evitar la despersonalización, esto es, evitar, en el mayor grado posible, las influencias de factores externos manipuladores o bien de factores internos que nos impiden el ejercicio de nuestra voluntad libremente. Una persona con sentido crítico acaba por convertirse en un sujeto con criterio propio, o sea, alguien sometido a principios y reglas continuamente regenerados, susceptibles de adaptarse a las diferentes circunstancias de la vida. En los contextos neoliberales actuales con cantidades ingentes de información circulando sin cesar en entornos persuasivos muy poderosos, para ser personas autónomas y críticas se precisa potenciar los procesos educativos, a la vez que alcanzar una distribución más igualitaria de los recursos y dispositivos formales disponibles (Vera, 2001). Realmente, la posesión de un criterio propio protege al sujeto de los procesos de alienación que amenazan su propia identidad personal. Denunciaba Fromm (1981) que la industrialización de las sociedades modernas requiere para su funcionamiento del hombre enajenado, de los hombres autómatas, capaces de fabricar máquinas que actúan como hombres y de producir hombres que funcionan como máquinas. Es como si la razón se relacionara de modo inversamente proporcional al crecimiento de la inteligencia. Alain Touraine (19981999) ha señalado que ante una situación dominada por la globalización, la innovación tecnológica, el mercado y la competitividad, la nueva sociología del trabajo se desarrolla como un instrumento de reconstrucción de una sociedad de la producción, de control social de la vida económica en la que el trabajo es una forma de resistencia a las presiones del mercado y de construcción de una identidad personal y colectiva. Para afrontar las alienaciones que conminan al ser humano, 
LA CONSTRUCCIÓN DE LA IDENTIDAD PERSONAL COMO PROYECTO DE EDUCACIÓN MORAL. SUPUESTOS TEÓRICOS Y DELIMITACIÓN DE COMPETENCIAS

la realización del sujeto constituye un fin que no puede quedar subordinado a ningún otro propósito. Cuando se carece de criterio propio, la alienación penetra en el individuo siempre para provecho de algo o de otros individuos (moda, religión, grupos de poder, consumismo, etc.). La formación del criterio propio presenta, pues, un carácter liberador para la persona y posibilita que no pierda su identidad. Pero supone un esfuerzo personal considerable, no es algo gratuito, e implica riesgo, porque a veces decidir y elegir lo mejor significa ir contra corriente, padecer presiones y encontrar resistencias de diverso género para el desenvolvimiento personal.

Con todas las limitaciones que nos muestra la ecología de la acción, el criterio propio nos convierte en seres morales y nos inclina al cumplimiento de lo deseable que no siempre coincide con lo deseado. Así, en ocasiones, el ser humano antepone a otros bienes la adhesión a unos valores determinados, la defensa de una forma de vida en la austeridad frente a la posibilidad de una existencia más confortable, la preservación de la propia identidad a cambio de situaciones de privilegio social o político... Sin caer en extralimitaciones acerca de la condición humana (Bourcier, 1968), únicamente a la persona de criterio cabe pedir verdaderamente responsabilidad: "Tiene responsabilidad quien tiene poder para hacer, quien no tiene poder para hacer no tiene responsabilidad. (Escámez y Gil, 2001, 26). El sujeto con criterio propio goza del autocontrol necesario para poder resistir los influjos ambientales y poner en práctica aquellas acciones que realmente quiere. Afirma Zygmunt Bauman, refiriéndose a los "dioses" contemporáneos (un partido, un veredicto histórico, una línea de progreso, una forma de ser humano, una ideología científica, un significado verdadero, una filosofía correcta), en todas sus incontables expresiones y disfraces, que estos dioses nos comunican uno y único mensaje: el derecho de unos cuantos a monopolizar el poder, la obligación de obedecer de los demás. Y agrega: "Sólo en la lucha contra esta unicidad se convierte el individuo humano, y el individuo humano como sujeto moral, en sujeto responsable, y puede nacer un sujeto que acepte la responsabilidad de su responsabilidad" (Bauman, 2001, 245).

Esencial a la educación moral, por tanto, es la capacidad de autorregulación del sujeto, la capacidad de dirigir por sí mismo su comportamiento. Esta capacidad trata de salvaguardar la iniciativa de la persona, su posibilidad, aunque limitada, de actuar de un modo voluntario, al margen de todas las presiones sociales que determinan patrones conductuales preestablecidos. Se entiende que el sujeto capaz de autorregularse se convierte, en la medida de lo posible, en verdadero agente de su conducta conforme a sus propios criterios morales (Escámez, 1998). El sujeto puede mostrarse así coherente entre lo que piensa y argumenta y lo que hace - logrando aquellos hábitos de comportamiento deseados-, entre el juicio y la acción moral, configurándose de esta manera un carácter o modo de ser propio de él, singular, único. 
ANTONIO BERNAL GUERRERO

LA CONSTRUCCIÓN DE LA IDENTIDAD PERSONAL COMO PROYECTO DE EDUCACIÓN MORAL. SUPUESTOS TEÓRICOS Y DELIMITACIÓN DE COMPETENCIAS

\subsection{Presentar sensibilidad emocional}

Nuestras acciones no dependen exclusivamente del componente cognitivo del sujeto, de su lógica, de su razón, sino también de nuestros sentimientos. Un cerebro reptiliano (médula espinal y bulbo raquídeo), lugar donde residen nuestras pulsiones más elementales, como la agresividad; un cerebro mamífero (paleocórtex), con el sistema límbico posibilitador del desarrollo de la afectividad; finalmente, el córtex y especialmente el neocórtex, específico de los humanos, sede de las operaciones de la racionalidad (Ratey, 2003). Con la evolución de las especies, estos cerebros se han superpuesto y no han desaparecido; he aquí nuestra naturaleza. No hay una jerarquía estable entre los tres cerebros, puede haber alteración de jerarquías. De modo natural, la razón no siempre manda sobre los sentimientos y controla las pulsiones. La región emocional es el sustrato sobre el que se desarrolló y evolucionó el cerebro racional y continúan estando en conexión a través de miles de circuitos neuronales. Por esta razón los centros emocionales inciden vivamente en el funcionamiento global del cerebro.

Tanto emociones como sentimientos básicos forman parte de nuestro equipamiento biológico, pero es definitivamente el ambiente cultural el que generalmente termina modulando cómo van a manifestarse o controlarse esas emociones y sentimientos en función de los símbolos, significados y patrones culturales del grupo en el que el individuo nace y crece. La moralidad no es el resultado ciego de emociones irracionales, pero tampoco un conjunto frío de principios racionales. El pensamiento tradicional ha tenido siempre dificultades para considerar las emociones desde la perspectiva de la racionalidad. No obstante, hay contextos en los que la evaluación racional debe considerar necesariamente el componente de sensibilidad emocional, particularmente en los grandes proyectos vitales, tan ligados a la educación moral. En este sentido, podría afirmarse que un fracaso afectivo absoluto es un fracaso racional (Broncano, 2001). No es extraño, pues, que en estos últimos años se haya insistido especialmente en la "inteligencia emocional" (Goleman, 1996) para enfatizar la importancia de la afectividad para la vida personal y colectiva, e incluso para el desarrollo mismo de los individuos, con el ánimo de contribuir favorablemente a la construcción de una cierta "sabiduría emocional" en las personas. La dotación biológica, la cultura y la estructura social, así como el desarrollo afectivo que experimenta un individuo terminan por edificar su dimensión emocional, por lo que una educación adecuada puede coadyuvar a forjar una personalidad afectivamente ajustada, con la repercusión positiva que ello tiene en la configuración de su identidad moral.

Comprender los sentimientos de los demás o percibir y canalizar las propias emociones constituyen capacidades básicas de esa sabiduría emocional ${ }^{18}$.

18. La capacidad para entender y comprender las propias emociones, así como los sentimientos de los demás, se halla íntimamente relacionada con la autoestima (LINDENField, 2001). Ésta surge de la evaluación que el sujeto realiza de sí mismo y de la consecuente respuesta afectiva al contenido de 
LA CONSTRUCCIÓN DE LA IDENTIDAD PERSONAL COMO PROYECTO DE EDUCACIÓN MORAL. SUPUESTOS TEÓRICOS Y DELIMITACIÓN DE COMPETENCIAS

Disfrutar de las relaciones con otras personas y poseer un nivel de confianza en uno mismo satisfactorio depende de nuestra inteligencia emocional, que va construyéndose a lo largo del desarrollo del propio sujeto, puesto que el temperamento no es el destino, aunque "cada uno de nosotros posee un temperamento innato, se mueve dentro de un espectro concreto de emociones, una característica que forma parte del bagaje con que nos ha dotado la lotería genética y cuyo peso se hace sentir a lo largo de toda la vida" (Goleman, 1996, 335). Presentar sensibilidad emocional constituye una competencia que el sujeto debe alcanzar para la configuración pertinente de su personalidad moral. En la conducta moral intervienen las emociones y sentimientos personales. Por tanto, es preciso poseer la sensibilidad requerida para percibir, asumir críticamente y saber emplear las propias emociones y sentimientos como elementos influyentes en la conciencia moral del sujeto. Con todo, en el propio desarrollo de la persona sus dimensiones emocional y moral mantienen una compleja interrelación. Ciertos sentimientos nos conducen al pensamiento y la acción morales y, a su vez, el conocimiento moral coadyuva al control emocional. Martha Craven Nussbaum (2003) ha insistido recientemente, analizando el pensamiento aristotélico y algunas de las principales escuelas filosóficas helenísticas, en el valor regulador que la alternativa moral puede ejercer sobre la vida de las personas, desvelando y formulando pensamientos y sentimientos profundos. Concibiendo la filosofía como un arte comprometido cuyo fin es la lucha contra la desdicha humana, al igual que lo hacían epicúreos, escépticos o estoicos, Nussbaum reclama el ejercicio crítico de la cultura, la dimensión terapéutica del filosofar, que presenta un efecto liberador de falsas creencias en tanto que los deseos y valores se han formado socialmente.

Desarrollar la capacidad de conocerse, de conocer los propios sentimientos, es el fundamento para la toma de conciencia emocional. En efecto, cuando hemos logrado aprender a percibir nuestras propias emociones, a ordenarlas y a aceptarlas, entonces tenemos la posibilidad de poder encauzarlas y gobernarlas. El conocimiento de sí mismo da opciones para desprenderse de sentimientos negativos y, al mismo tiempo, posibilita cierta optimización vital ligada a la capacidad de autodominio que experimenta el sujeto. El autoconocimiento progresa paralelamente a

\footnotetext{
dicha evaluación. Junto a las atribuciones que aluden a los juicios sobre las causas de los resultados en distintos ámbitos comportamentales y al éxito o fracaso en campos muy valorados por la persona, tanto la comparación social como la valoración recibida por parte de otras personas inciden claramente en la constitución de la autoestima. A mayor dependencia de los demás estos últimos factores adquieren más relevancia. Por eso es tan importante la calidad humana de la relación con los niños, dependientes de los adultos para tantas cosas, puesto que la formación de su autoestima dependerá en gran medida del tipo de relaciones afectivas que mantengan con las personas que están en su entorno más próximo. Esto es válido igualmente para aquellos adultos que por distintas razones (inmadurez psicológica, deficiencias de diverso orden) muestran una excesiva dependencia de los demás con la consiguiente influencia en la conformación de su autoestima. Potenciar un autoconcepto basado en la propia acción y sus consecuencias preserva de la construcción de la autoestima exclusivamente como percepción imaginada de los otros, aunque siempre dependerá en uno u otro grado de la valoración de los demás.
} 
LA CONSTRUCCIÓN DE LA IDENTIDAD PERSONAL COMO PROYECTO DE EDUCACIÓN MORAL SUPUESTOS TEORICOS Y DELIMITACIÓN DE COMPETENCIAS

la conciencia de identidad personal del sujeto (Harris, 1992; Cobo Paredes, 2003). Es posible el cultivo de la capacidad de controlar y gestionar las propias emociones, los impulsos y las situaciones afectivas en las que el sujeto pueda encontrarse. Básicamente, se trata de controlar la acción: evitando ciertas conductas inadecuadas, aplazando comportamientos y cambiando las estrategias conductuales si es preciso $^{19}$. Todo ello está relacionado con la consolidación de comportamientos orientados a la fuerza de voluntad, al esfuerzo razonado y razonable, a la capacidad de sacrificio o de autoexigencia. Esta capacidad del sujeto se hace tanto más necesaria cuanto más fácilmente se ve arrojado, desde múltiples instancias, a fórmulas hedonistas rudimentarias, al consumo irreflexivo momentáneo, a la acción vertiginosa y a menudo gregaria, buscadora de satisfacciones inmediatas, que nada tienen que ver frecuentemente con el disfrute de bienes ajustados a las exigencias de la inteligencia y de la sensibilidad (Guisán, 1990), más proclives al goce profundo y duradero. En este sentido, parece necesario educar en la capacidad de tolerar la frustración, que nada tiene que ver con incitar al abandono de metas o tareas, sino más bien con fomentar la capacidad de superación de obstáculos, transmitiendo el valor del esfuerzo como medio para alcanzar los objetivos. El reconocimiento y control positivo de las emociones y sentimientos en la configuración de la acción moral predispone asimismo para la comprensión y entendimiento de los sentimientos de los demás.

Vinculada a la sabiduría emocional se halla la capacidad de percibir los sentimientos de los otros. No hay desarrollo de la inteligencia emocional sin el contacto interpersonal, sin interacción emocional entre un sujeto y otro u otros sujetos. Se trata de adquirir la sensibilidad necesaria para poder valorar el dolor ajeno -recorriendo la gama de emociones pertinentes: piedad, benevolencia, amargura, rabia, indignación, solidaridad, etcétera-, para poder reflexionar sustancialmente sobre el sufrimiento de los demás y poder actuar para aliviarlo o eliminarlo si está a nuestro alcance. Esta capacidad entraña, pues, un evidente grado de compromiso con el otro, también nos hace partícipes de su suerte (Ortega y Mínguez, 2001). Cultivar los procesos empáticos, para los que hay una disposición natural en el sujeto como la hay para la agresividad o el odio (Cobo Paredes, 2003), resulta decisivo para la construcción de la competencia emocional.

\subsection{Manifestar prosocialidad}

Unida estrechamente al ámbito afectivo, se encuentra la esfera de lo social. De hecho, fácilmente encontramos programas educativos para desarrollar la competencia social que, en realidad, son programas socioafectivos (Trianes, 1996; Roche y Sol, 1998). Efectivamente, la competencia social se manifiesta en el dominio de

19. La gestión constructiva de los conflictos desde las aulas puede considerarse en clave preven tiva y base operativa de alfabetización emocional (SANTOS REGO, 2001). 
ciertas habilidades sociales, que siempre suponen algún género de evaluación por parte de los otros con la correspondiente implicación emocional favorable o desfavorable, pero también forma parte de ella la asunción individual, cognitiva y socioemocional, de una disposición conductual prosocial. La prosocialidad presenta un gran valor moral, puesto que con ella no se hace referencia a una mera cooperación -entendida como distribución de esfuerzos, costes y beneficiossino que se alude a la realización de conductas favorecedoras para otras personas, grupos o metas sociales, sin búsqueda por parte del sujeto de recompensa alguna. En las relaciones interpersonales, una conducta prosocial aumenta la probabilidad de generar una reciprocidad positiva, solidaria, sin perderse la identidad de las personas o grupos implicados. La cordialidad y la confianza en el otro nos abren al mundo que nos rodea iluminándolo de algún modo y recibiendo de él igualmente cierta plenitud, algún sentido. La asistencia física a otras personas que la precisan para cumplir un determinado propósito; dar y compartir objetos, ideas, experiencias; palabras de apoyo o consuelo; manifestaciones para confirmar el valor de otras personas o aumentar su autoestima; la acogida y la escucha atenta y profunda; el compromiso de compartir consecuencias penosas o desgraciadas para otros; la presencia y proximidad personal en los momentos oportunos, constituyen claros ejemplos de manifiesta prosocialidad. Por otra parte, como ya hemos advertido, las acciones prosociales tienden a hacerse recíprocas multiplicando sus efectos en las diferentes interacciones. Así, se minimiza el riesgo de conflictos violentos, se incrementa la flexibilidad y se evita el dogmatismo mediante la actitud empática, se estimula la comunicación, se aumenta la sensibilidad emocional respecto de los demás, probablemente se mejora la percepción de personas y en las personas y se refuerza el autocontrol.

Las babilidades sociales hacen más eficaces nuestras relaciones interpersonales. Sin duda alguna, hay que desarrollarlas adecuadamente desde los primeros momentos en que ello es posible, especialmente desde que el niño abandona su egocentrismo psicológico y es capaz de situarse cognitivamente en otros puntos de vista (Muñoz, Trianes y Jiménez, 1994). Las habilidades sociales son imprescindibles para que se pueda realizar una adaptación social equilibrada, saludable. La capacidad de adaptación a los distintos contextos sociales y la posibilidad de establecer relaciones sociales satisfactorias tanto con los uguales" como con los que no lo son depende de nuestras habilidades sociales. Cuando disponemos de un buen repertorio de habilidades sociales ${ }^{20}$ incrementamos nuestras posibilidades de bienestar. Al tratarse de conductas sociales específicas, las habilidades dependen del contexto en el que han de desarrollarse, de los parámetros (edad de las personas

20. Las habilidades sociales representan conductas complejas que contienen componentes motores, emocionales y cognitivos, y se caracterizan por ser respuestas específicas a situaciones específicas (hay pocos comportamientos sociales apropiados para todas las situaciones). Estas habilidades se aprenden. Podríamos destacar las siguientes habilidades: de interacción social, para hacer amigos, conversacionales, para resolver problemas. 
que intervienen, género, objetivos planteados, lugar, etc.) de la situación concreta de que se trate. Las habilidades no pueden disociarse del medio en que se insertan. En este sentido, las interacciones entre iguales, y no sólo entre adultos y niños, se han revelado como importantísimas para la configuración de habilidades y para el propio desarrollo personal (Monjas, 1995).

A partir de las específicas condiciones de interacción que ofrecen los diversos espacios (familiar, laboral, escolar, lúdico, etc.) se pueden desarrollar las habilidades sociales y la conducta prosocial en el sujeto. El reconocimiento del valor de la comunidad y de la asimilación crítica de las normas colectivas para su buen funcionamiento constituye una capacidad que debe ser desarrollada. Adquirir normas convivenciales es necesario si queremos una correcta vida colectiva, lo cual no impide su crítica y su revisión permanente en busca de logros más justos (Medina Rubio, 2002). La educación moral no puede desligarse de las experiencias que nos brinda la vida comunitaria. La construcción de la propia identidad se realiza en el seno de la comunidad. La acción pedagógica sistemática sobre el ámbito de la educación moral es una condición necesaria para alcanzar un nivel de alfabetización funcional suficiente en sociedades plurales y democráticas (Martínez, 1995). En este sentido, se enfatiza la necesidad de la integración participativa en las comunidades próximas, ya que esas pequeñas comunidades, esas asociaciones, "fomentan el autogobierno y la unión entre los ciudadanos para exigir el respeto a sus derechos civiles, políticos, sociales o de calidad de vidan (Escámez y Gil, 2001, 40). La capacidad de reflexionar criticamente sobre las formas de vida y tradiciones valorativas de las comunidades se halla en el núcleo de una educación para una ciudadanía responsable. De este modo, los ciudadanos podrán asumir la responsabilidad de participar dignamente en la reconstrucción social (Ortega y Mínguez, 2001). Comprender y adoptar nuestra responsabilidad como ciudadanos significa que hemos de creernos que somos verdaderamente agentes de la democracia y que, desde nuestra autonomía, hemos de darnos nuestros propios principios, respondiendo de nuestros actos, encaminados a la difícil pero apasionante tarea de construir un mundo más habitable.

\subsection{Mostrar sentido creativo en el ámbito de los valores}

La construcción de la conciencia moral, que inicialmente no es un proceso autorreferencial sino dependiente de la interacción social y comunicativa, es posible por los procedimientos de deliberación y acción moral (juicio, comprensión, autorregulación). No se trata de una conciencia entendida como capacidad ilimitada e indeterminada tanto en su conocimiento como en su orientación. Precisamente se considera conciencia moral autónoma ese conjunto de procedimientos que hacen posible la autodeterminación, o sea, establecer por uno mismo qué se considera correcto, y, además, ser capaz de actuar con coherencia respecto de lo considerado correcto implicándose personalmente en la acción (Puig, 1996). La identidad moral del sujeto se va construyendo en el enlace entre los procedimientos reseñados y los valores hacia los que se orientan dichos procedimientos. 

SUPUESTOS TEÓRICOS Y DELIMITACIÓN DE COMPETENCIAS

Todo individuo nace en una cultura, que siempre supone una interpretación de la realidad, pero que se le representa como "la realidad. Cada persona, en su percepción del mundo, se enfrenta a las cosas pero sentimentalmente percibidas. Todas las indicaciones y preceptos morales que recibimos de las generaciones anteriores se encuentran como sedimentados en una cultura concreta, llegándonos casi como supersticiones, cuando ya hemos olvidado las causas que los generaron. Las distintas tradiciones morales han sido configuradas por un compendio de accidentes históricos originados por un deseo permanente de supervivencia y de felicidad. Se tiene la impresión de que muchas normas morales son síntesis contundentes de soluciones a problemas ya olvidados, que podrían explicarse, pero que resultan más eficaces si se imponen imperativamente por la obligación moral. La moral que recibimos en una cultura determinada está plagada de contenidos implícitos, muchos de ellos de ancestral explicación (Harris, 1993). En las diversas tradiciones morales encontramos autoridades, normas, sistemas de controles y sentimientos ligados a la experiencia moral. A través de las instituciones socializadoras, cada cultura transmite un corpus de deberes. En un marco de elevada complejidad sentimental, al niño le llegan los deberes establecidos desde fuera, integrándolos en un modelo. Tal modelo es proporcionado inicialmente por la sociedad, y se trata de un modelo mental para ser realizado, es decir, sugeridor de la acción mediante unas reglas u obligaciones. No faltan razones para hacerlo: integrarse en el medio social, ser aceptado y querido, hacer lo que se espera de uno, huir de la culpa o de la vergüenza, estar orgulloso de uno mismo, evitar el castigo, ser alabado. Estos sentimientos nos unen afectivamente con el modelo propuesto y pueden esclavizarnos. La presión de dicho modelo termina, frecuentemente, en rutina, presentándose muchas obligaciones como costumbres. Éstas, cuando se convierten en hábitos atemperan el deber, que pasa a ser casi como natural, como una naturaleza añadida a la naturaleza. Este modelo representa un proyecto general de vida que se acepta sin reflexión, con la misma ingenuidad que caracteriza la aceptación de las normas del lenguaje, y que cada sujeto hará concreto de un modo determinado. Con el paso del tiempo, al entrar el modelo en crisis por algún motivo, la persona puede preguntarse por qué tiene que aceptar ese modelo, y la respuesta puede ser transgresora, apartada de la moral vigente en su cultura (Marina, 1995). La creación ética pasa por la superación de estas morales de primera generación, convencionales, para poder articular morales de segunda generación, legitimadoras de la diversidad, de la riqueza creativa de las diferentes culturas, y configuradas desde un mayor conocimiento de la acción moral, de su sentido y su alcance. En este sentido, se ha proclamado la necesidad urgente de una ética, considerada como moral universal, transcultural, en la que puedan encontrar solución los graves problemas que aquejan hoy a la humanidad. El sentido creativo en el dominio de los valores demanda una actitud crítica hacia cualquier forma de ser o vivir que la realidad parezca imponer, porque "ser humano consiste en buscar la fórmula de la vida humana una y otra vez» (Savater, 2003, 33). 
No se trata, evidentemente, de rechazar por completo todos los elementos de las tradiciones morales. Aunque en ocasiones su aplicación específica pueda resultar discutible y dependiente de ciertos contextos culturales o de determinadas etapas históricas, lo cierto es que podemos hablar de un conjunto de valores que consideramos universalmente deseables ${ }^{21}$. Estos valores merecen ser cultivados a través de la educación moral. Sin embargo, su reconocimiento y asimilación no significa que las personas se cierren a nuevas consideraciones valorativas cuando tales valores se aplican a determinadas especificidades o cuestiones problemáticas en las que surgen nuevos dominios de acción moral. Muestra de lo que decimos podría ser, desde la perspectiva de la colectividad, el proceso de reconocimiento de los derechos humanos de "primera generación" o de "segunda generación", relacionados más directamente con los derechos donde el Estado tiene un papel destacado para que se cumplan, aunque estos últimos representaron un avance en los planos económico y social, así como sucede con los denominados derechos de "tercera generación" o de "cuarta generación", que han acentuado progresivamente la responsabilidad de cada persona (Ballesteros, 1992). Desde el ángulo individual, el sujeto puede igualmente luchar por lograr una forma de vida personal abierta y creativa en el ámbito de los valores. En este sentido, nos parece fundamental que el sujeto desarrolle las capacidades de participación democrática y de acción comprometida con la realidad social en la que se halla inmerso. A través de la participación social (Escámez y Gil, 2001) la persona puede disponerse a adquirir determinados compromisos de acción donde pueda contrastar sus propios proyectos con la realidad comunitaria en busca de una sociedad más libre y justa. Pero para poder contrastar proyectos es preciso tenerlos, o sea, es conveniente que el sujeto trate de hallar incesantemente sus propias claves de valor, cultivando el conocimiento de sí mismo, desarrollando la capacidad de composición de la propia vida personal, de las trayectorias autobiográficas, sobre las que poder construir un proyecto de vida deseable. A la postre, avanzar en cultura democrática supone estar buscando constantemente lo que más nos conviene hacer para que nadie quede dañado en la exclusión; implica, igualmente, aumentar la capacidad de información y de decisión de cada persona respecto del modo de vida que haya elegido para sí. Significa enseñar al niño a que busque por sí mismo su estilo de vida, facilitándole los medios que le conviertan en un ser autónomo y tolerante con las decisiones privadas de cualquier otra persona. Cultura moral y democrática, en fin, supone producción continua de símbolos que impulsen y motiven a vivir en la sociedad pluralista ejercitándose en la vida privada más libre.

21. Por ejemplo, Plig Rovira (1995) ha destacado los siguientes valores. Desde una perspectiva macroética o pública: justicia, libertad, igualdad, solidaridad, benevolencia, tolerancia, respeto, participación, compromiso y cooperación. Desde una perspectiva microética o privada: renuncia, reconocimiento, verdad, apertura a los demás, empatía, consideración, amor, coherencia, responsabilidad y voluntad de valor. Como valores comunes a ambos espacios éticos destaca la autonomía y la crítica. 
LA CONSTRUCCIÓN DE LA IDENTIDAD PERSONAL COMO PROYECTO DE EDUCACIÓN MORAL. SUPUESTOS TEÓRICOS Y DELIMITACIÓN DE COMPETENCIAS

\section{CONCLUSIONES}

Una arqueología actual de la identidad personal nos sugiere una profunda reconceptualización, una reorganización conceptual compleja que va más allá del simple traslado del punto de vista autocentrado clásico a la perspectiva heterocentrada del sujeto. Ésta ha supuesto, a no dudarlo, un giro copernicano respecto del tradicional enfoque del sujeto, "ptolomeico" podría decirse, que terminaba por constituirlo en el fundamento trascendental de cualquier otra realidad. En efecto, no hay propiamente sujeto sin los otros, sin otros sujetos que están ahí desde el principio para contribuir decisivamente a su propia configuración. De aquí se desprenden dos tentaciones: considerar al sujeto como principio mágicamente explicativo de todo lo demás, incluso cayendo en el riesgo de la interpretación solipsista; entender que el sujeto en realidad es mero producto de los contextos socioculturales e históricos en los que se halla inmerso. Desde una preocupación primaria por el sujeto, lo cual no invalida una visión cósmica de la realidad, la identidad del sujeto hace sentido formal, como bucle integrador, reintegrador, de las múltiples manifestaciones del sí mismo en las que el sujeto queda fragmentado, en las que corre el riesgo incluso de no reconocerse, al menos parcialmente, de un modo dramático y aun trágico.

Frente a la posición sustancialista de la identidad se han ido acentuando los procesos de disolución de la subjetividad y autonomía del hombre bajo una nueva heteronomía. Pero la crisis antropológica no implica renunciar a la identidad de la persona como idea regulativa, sino más bien interrogarnos por las instancias humanizadoras, por el sujeto y su argumento vital. La singular animalidad del ser humano está íntimamente vinculada a formas de expresión cultural. Precisamente la identidad puede entenderse como clave de comprensión de la estructura y patrón de los procesos educativos. Así lo expresan García Carrasco y García del Dujo:

La tarea fundamental de la reflexión sobre la educación es precisamente estar atento a todo ese recorrido de los humanos como especie dentro del mundo de la vida, recorrido que empieza precisamente reproduciendo el diseño de la especie en un cuerpo que no puede sobrevivir sino incorporándose a un espacio relacional compuesto por comunidades de humanos; ahí toma modos de ser y estilos de hacer, desarrolla unas capacidades y se inhibe en otras; allí es donde construye la obra más maravillosa, compleja, exclusiva, participada, comprometida, afiliada, poliédrica, a la que todos señalamos como identidad. Construir esa identidad es el objetivo de todo el proceso de formación y comprender ese proceso es el objetivo fundamental de la teoría de la educación (2001, 41).

El hecho de ser animales simbólicos, seres culturales capaces de inventar, de crear, supone un salto cualitativo respecto de la existencia de las demás especies animales. Aquí se inicia lo que denominamos propiamente bombre, aunque continúa abierta la pregunta fascinante acerca de su verdadero origen, sobre cuál es el punto de inflexión que dio inicio no ya a la continuación del mundo natural realizada con su inteligencia y con sus manos, sino a la creación de un universo 
LA CONSTRUCCIÓN DE LA IDENTIDAD PERSONAL COMO PROYECTO DE EDUCACIÓN MORAL. SUPUESTOS TEORICOS Y DELIMITACIÓN DE COMPETENCIAS

simbólico prolongador del mundo físico, capaz de posibilitar la acumulación y crecimiento de un patrimonio cultural que ha ido progresivamente aumentando las posibilidades de acción racional, de potencialidad operativa, de la especie y de los individuos gracias a sus extraordinarias posibilidades de aprendizaje. No estamos, en modo alguno, determinados a vivir en una zona concreta de la Tierra bajo determinadas condiciones, como acontece con otras especies, en cambio sí precisamos de otros seres humanos desde el principio de nuestra existencia para que nos ayuden y enseñen, para que nos transmitan símbolos prácticos de lo que somos y hacemos, a partir de los cuales podamos asimismo ser y hacer.

Posiblemente, en el acto de elegir se sitúa el dinamismo de la acción humana, recordando aquella advertencia kantiana sobre la paradoja de que la necesidad de actuar es mayor que la posibilidad de conocer. Ahora bien, la acción humana no se desencadena a modo de una creación absoluta e infalible; no siempre sabemos totalmente lo que hacemos aunque hagamos lo que sabemos. Lejos de resignarnos a un escepticismo generalizado, afrontar nuestro mundo incierto supone ser conscientes de la ecología de la acción. Ésta comporta, primeramente, que una acción ejecutada entra en un juego de interacciones y retroacciones en el ámbito donde se efectúa, que no sólo pueden desviarle de sus fines sino conducir a un resultado totalmente contrario al esperado. En segundo lugar, la ecología de la acción manifiesta que las consecuencias últimas de la acción son impredecibles (Morin, 2001). Normalmente, cuando vamos a actuar no disponemos de todo el conocimiento seguro y fiable en que va a inscribirse nuestra acción. No es infrecuente actuar desde una perspectiva de probabilidades y de certezas cuestionables, lo que nos arroja a la incertidumbre, por otra parte inevitable en nuestra condición humana -nunca lo sabemos todo, nunca estamos completamente seguros de saber lo suficiente- En no pocas ocasiones nos vemos obligados a elegir necesariamente entre opciones que no nos satisfacen (fatalidad) y que, desde luego, en otras circunstancias no elegiríamos. Las carencias y las constricciones que presentan nuestras acciones pueden incluso producirnos serios daños, pero no nos impiden actuar. De hecho en muchas ocasiones nos vemos forzados a actuar en contextos de fatalidad. Esto no significa que lo genuino de los actos humanos no es que sean intencionales, prácticos en el sentido de que demuestran la capacidad de acción del ser humano (Searle, 2000). Desde la asunción, pues, de la complejidad y la incertidumbre de los fenómenos humanos y, por tanto, del fenómeno moral, planteamos el proyecto educacional de construcción de la identidad personal, considerándola como construcción discursiva autorreferida y situada en un contexto de interacción social, puesto que la identidad se construye necesariamente en las demandas de interacción en las que estamos implicados como sujetos.

El tradicional planteamiento bifronte entre éticas teleológicas o consecuencialistas y éticas deontológicas o no consecuencialistas desaparece al amparo de las éticas deontológicas actuales. Éstas se constituyen como éticas consecuencialistas. Más bien, el criterio para distinguir entre éticas teleológicas y deontológicas consiste en descubrir a qué aspecto del fenómeno moral se da prioridad: a lo bueno o 
a lo justo. Una ética deontológica entiende que la ética ha de centrarse en el marco de lo que es justo en ella, ya que lo que cada uno considera su bien, lo que cada uno cree que es bueno para él, debe determinarlo él mismo dentro del marco de lo que es justo. Lo justo aparece así como universalmente exigible, en tanto que racional, mientras que lo bueno depende en última instancia de cada individuo y de los diversos grupos sociales. Una ética teleológica, en cambio, considera que la ética puede y debe aclarar qué es lo bueno para las personas y, desde esa propuesta del bien, la opción más correcta moralmente será la que lo lleve a su plenitud. Las éticas deontológicas actuales, que son consecuencialistas, parecen ofrecer una plataforma teórica válida para la elaboración de una educación moral centrada en la autonomía de la persona, ofreciendo una posible solución al tradicional problema de la "falacia naturalista". La realización de la libertad reclama la concreción de la moralidad en las instituciones, las costumbres y los hábitos comunitarios; pero la educación moral no puede desprenderse, al mismo tiempo, de la preocupación nuclear por las actitudes de las personas, más allá de los bienes que puedan conseguirse, por la capacidad crítica de los sujetos, más allá de la adaptación a una comunidad.

La investigación en torno a la identidad personal suscita actualmente un interés renovado, tratándose de indagar en la realización bidireccional entre los cambios socioculturales y los cambios en la manera de entender y describir nuestra propia identidad personal. Un buen número de estudios se centran en la naturaleza y funcionalidad de la identidad del sujeto en detrimento de los estudios de búsqueda de diferencias individuales (Monsalve, 1997). Ahora bien, ya no parece pertinente plantearnos la construcción de la identidad desde enfoques teóricos de un dominio indivisible del yo (Erikson, 1968; Kegan, 1979; Loevinger, 1976), implicado al mismo tiempo en diversos tipos de actividades estructuradoras (lógicas, interpersonales, morales y aun metafísicas), sino más bien desde perspectivas teóricas que hipotetizan la existencia de diversas trayectorias en el curso de la vida, de algún modo relacionadas pero diferenciadas dentro de un sujeto multifacético e imperfectamente unificado. Desde este punto de vista, con diferentes matizaciones en torno a los procesos de unificación o de reunificación de la identidad, se han elaborado propuestas teóricas diversas según a qué subdominio estructural nos refiramos: cognitivo, social, moral (Fowler, 1981; Gilligan, 1985; Labouvie-Vief, 1992; White, 1987).

La propuesta delimitadora de competencias educativas en el ámbito moral que aquí se ha formulado encaja con todas estas preocupaciones por la identidad personal. Juzgamos conveniente ensanchar el campo del enfoque formativo de las competencias ya existente. En efecto, parece deseable establecer propuestas de educación moral desde el enfoque de formación en competencias. Nuestra propuesta se realiza desde la pretensión de contribuir, decidida pero cautelosamente, a la vertebración de un amplio enfoque optimizador del cliclo vital del individuo, para el cual los recursos educacionales de la persona para afrontar la realidad son determinantes. Tal enfoque adopta, dentro de los márgenes que permite la 
LA CONSTRUCCIÓN DE LA IDENTIDAD PERSONAL COMO PROYECTO DE EDUCACIÓN MORAL. SUPUESTOS TEÓRICOS Y DELIMITACIÓN DE COMPETENCIAS

condición humana, una visión indeterminada de la identidad del sujeto y aspira a constituirse en viático para las posibilidades de crecimiento autónomo personal. Pero somos conscientes de las limitaciones que ofrece este tipo de propuestas formativas (Bernal, 2003). La transferibilidad de las competencias -imprescindible para el logro del éxito de lo aprendido en contextos diferentes a los iniciales de aprendizaje - presenta no escasas dificultades, puesto que las habilidades transferibles están normalmente sometidas a las condiciones y límites de cada dominio concreto, lo que complica su potencialidad descontextualizadora. Por otra parte, la posibilidad de que los recursos personales adquiridos en el proceso formativo actúen como foco dinamizador de estructuración y de integración equilibradora en el sujeto, se halla sometida a una experiencia de disonancias tanto intersubjetivas como intrasubjetivas de alta complejidad (familiares, laborales, políticas...). El posible éxito de propuestas formativas en competencias dentro del ámbito moral dependerá, en última instancia, de haber podido traducir a competencia humana la maximización de las oportunidades de emancipación personal, la capacidad de crítica y autocrítica de ideas, afirmaciones, símbolos, instituciones, ideologías y posturas éticas. En última instancia, el problema pedagógico central, en este punto, reside en cómo facilitar el acceso a los sujetos a identidades valiosas, positivamente configuradas. La desconsideración de la construcción de la identidad como proyecto de educación moral conduce a la percepción de ausencia de valor de la propia biografía, a una paupérrima crónica del "yo"; pero también condena a las identidades fragilizadas a una lucha incesante, de incierto pronóstico, por presentarse ante los otros como interlocutores sujetos de derechos en la interacción social.

Ser conscientes de la complejidad que encierran los procesos de construcción de la identidad, por de pronto, nos previene de falsos optimismos pedagógicos, que no es poco, pero no supone abandonarnos a un escepticismo más o menos ilustrado. Se trata de prepararnos para afrontar la incertidumbre:

Todos debemos ser plenamente conscientes de que nuestra propia vida es una aventura, incluso cuando la creemos encerrada en una seguridad funcional; todo destino humano comporta una incertidumbre irreductible, comprendiendo en ella la certeza absoluta, que es la de su muerte, ya que ignora la fecha. Cada uno debe ser plenamente consciente de participar en la aventura de la humanidad que es lanzada a lo desconocido con una rapidez cada vez más acelerada (Morin, 2001, 81).

Para que no nos cieguen falsas certezas, de las que nuestro acervo cultural está colmado, los compromisos fundamentales de nuestras vidas, individuales y colectivas, nuestros compromisos morales, lejos de toda resignación escéptica, parecen reclamarnos una vigorosa lucha, lúcidamente sostenida desde una esperanza incierta. 

SUPUESTOS TEÓRICOS Y DELIMITACIÓN DE COMPETENCIAS

\section{BIBLIOGRAFIA}

AlLPORT, G. W. (1988) La persona en psicología. México, Trillas.

APEL, K. O. (1986) Estudios éticos. Barcelona, Alfa.

- (1990) Una ética de la responsabilidad en la era de la ciencia. Buenos Aires, Almagesto. ARISTÓTELEs (1970) Ética a Nicómaco. Madrid, Instituto de Estudios Políticos.

Bailesteros, J. (1992) Los Derechos Humanos. Madrid, Tecnos.

Bauman, Z. (2001) La posmodernidad y sus descontentos. Madrid, Akal.

BERGER, P. L. y LUCKMANN, T. (1967) The social construction of reality: a treatise in the sociology of knowledge. Middlesex, Penguin Books.

Bernal, A. (2002) Reconceptualización de la idea de sujeto y educación, en Bernal, A. (coord.). Persona, curriculum y postmodernidad. Barcelona, PPU, 25-62.

- (2003) El constructo "madurez personal" como competencia y sus posibilismos pedagógicos, Revista Española de Pedagogía, Lxi (225), 243-261.

BOURCIER, A. (1968) La nouvelle éducation morale: pour en faire des responsables et non pas des anxieux. París, Éditions Sociales Françaises.

Broncano, F. (2001) La educación sentimental. O de la difícil cohabitación de razones y emociones, Isegoria, 25, 41-61.

BRUNER, J. (1991) Actos de significado. Más allá de la revolución cognitiva. Madrid, Alianza.

Cobo PARedes, M. ${ }^{a}$ V. (2003) Quién soy yo". Madrid, Acento.

Derrida, J. (1994) Márgenes de la filosofía. Madrid, Cátedra.

Erikson, E. H. (1968) Identity. Youth and crisis. Nueva York, Norton.

EsCÁmeZ, J. (1998) Educar en la autonomía moral. Valencia, Generalitat Valenciana.

EsCÁmEZ, J. y Gil, R. (2001) La educación en la responsabilidad. Barcelona, Paidós.

FIERro, A. (2002) Personalidad, persona, acción. Un tratado de psicología. Madrid, Alianza Editorial.

FOWLER, J. W. (1981) Stages of faith: the psychology of buman development and the quest for meaning. San Francisco, Harper \& Row.

Fromm, E. (1981) La condición bumana actual. Barcelona, Paidós.

García Carrasco, J. y García Del Dujo, A. (2001) La teoría de la educación en la encrucijada, Teoria de la Educación. Revista Interuniversitaria, 13, 15-43.

Gargallo, B. y García López, R. (1996) La promoción del desarrollo moral a través del incremento de reflexividad. Un programa pedagógico, Revista de Educación, 309, 287-308.

Gilugan, C. (1985) La moral y la teoría. Psicología del desarrollo femenino. México, FCE.

Goleman, D. (1996) Inteligencia emocional. Barcelona, Kairós.

GORDON, C. Y GERGEN, K. J. (eds.) (1986) The self in social interaction. Nueva York, Wiley.

GREENWALd, A. G. (1980) The totalitarian ego: Fabrication and revision of personal history, American Psychologist, 35, 603-618.

Grisez, G. y Shaw, R. (1993) Ser persona. Curso de ética. Madrid, Rialp.

Gussán, E. (1990) Manifiesto bedonista. Barcelona, Anthropos.

HABERMAs, J. (1985) Conciencia moral y acción comunicativa. Barcelona, Península.

- (1988) Pensamiento postmetafísico. Madrid, Taurus.

HARRIS, M. (1993) Vacas, cerdos, guerras y brujas. Madrid, Alianza.

HARRIS, P. H. (1992) Los niños y las emociones. Madrid, Alianza.

Hartmann, N. (1954) Ontología r. Fundamentos. México, Fondo de Cultura Económica.

KeGAN, R. (1979) The envolving self: A process conception for ego psychology, The Counseling Psychologist, 8 (2), 5-34. 
LA CONSTRUCCIÓN DE LA IDENTIDAD PERSONAL COMO PROYECTO DE EDUCACIÓN MORAL. SUPUESTOS TEÓRICOS Y DELIMITACIÓN DE COMPETENCIAS

KOHLBerg, L. (1981) Essays on moral development. The philosophy of moral development (vol. I). Nueva York, Harper \& Row.

LABOUvie-VIEF, G. (1992) A neo-Piagetian perspective on adult cognitive development, en SternBerg, R. J. y BerG, C. A. (eds.). Intellectual development. Nueva York, Cambridge University Press, 197-228.

Lindenfield, G. (2001) Autoestima. Barcelona, Plaza \& Janés.

Loevinger, J. (1976) Ego development. San Francisco, Jossey-Bass.

López Aranguren, J. L. (1976) Ética. Madrid, Alianza.

MaCINTYRe, A. (2001) Animales racionales y dependientes. Barcelona, Paidós.

Marina, J. A. (1995) Ética para náufragos. Barcelona, Anagrama.

MARTiNeZ, M. (1995) La educación moral: Una necesidad en las sociedades plurales y democráticas, Revista Iberoamericana de Educación, 7, 13-19.

MasLow, A. (1962) Toward a psychology of being. Nueva York, Princeton.

MEdiNa RuBio, R. (2002) La formación en los valores de los derechos bumanos, fundamento de la convivencia y de la paz (Discurso de ingreso como Académico de Número). Madrid, Real Academia de Doctores.

MonjAs, M. I. (1995) Programa de enseñanza de babilidades de interacción social. Madrid, CEPE.

Monsalve, V. (1997) La psicología del "self" según "Psychological Abstracts" (1980-93). Consideraciones generales, Boletin de Psicologia, 55, 63-76.

MoOre, G. E. (1962) Principia Ethica. Cambridge, Cambridge University Press.

MoRIN, E. (2001) La mente bien ordenada ( $3^{a}$ edición). Barcelona, Seix Barral.

- (2002) El método. La bumanidad de la bumanidad. Madrid, Cátedra.

MuÑoz, A.; Trianes, M. ${ }^{2}$ V. y Jiménez, M. (1994) Una propuesta de educación de la competencia para las relaciones interpersonales a través del nuevo currículum educativo, Infancia y Sociedad, 24, 49-77.

Nussbaum, M. C. (2003) La terapia del deseo: Teoria y práctica en la ética belenística. Barcelona, Paidós.

Ortega y Gasset, J. (1983) Meditaciones del Quijote (Obras Completas, tomo I). Alianza, Madrid y Revista de Occidente.

Ortega, P. y Mínguez, R. (2001) La educación moral del ciudadano de boy. Barcelona, Paidós.

Pérez, P. M.; Cánovas, P. y Gervilla, E. (1999) Valores, actitudes y competencias básicas en la enseñanza obligatoria, Teoría de la Educación. Revista Interuniversitaria, 11, 53-83.

Pug, J. M. ${ }^{2}$ (1995) La educación moral en la enseñanza obligatoria. Barcelona, ICE de la Universitat de Barcelona/Editorial Horsori.

- (1996) La construcción de la personalidad moral. Barcelona, Paidós.

RABINOw, P. y SuluIvan, W. M. (eds.) (1979) Interpretative social science. Berkeley, Univ. California Press.

RATEY, J. J. (2003) El cerebro: Manual de instrucciones. Barcelona, Grupo Editorial Random House Mondadori, S.L.

RAWLs, J. (1978) Teoría de la justicia. México, FCE.

RuCOEUR, P. (1990) Soi-même comme un autre. París, Seuil.

ROCHE, R. y SOL, N. (1998) Educación prosocial de las emociones, valores y actitudes positivas. Para adolescentes en entornos familiares y escolares. Barcelona, Blume.

SACKs, O. (1985) The man who mistook his wife for a bat. Nueva York, Summit Books.

SANTOS Rego, M. A. (2001) La habilitación mediacional y la mejora de la convivencia en la escuela, Bordón, 53 (2), 299-310. 
Sarramona, J. (2003) Los indicadores de la calidad de la educación, en AA.VV., Calidad, equidad y educación. San Sebastián, Erein, 33-64.

Savater, F. (2003) El valor de elegir. Barcelona, Ariel.

SCHELER, M. (1941) El formalismo en la ética y la ética material de los valores. Madrid, Revista de Occidente.

SCHÖN, D. (1987) Educating the reflective practitioner. Londres, Jossey-Bass.

SEARLE, J. R. (2000) Razones para actuar. Oviedo, Nobel.

SLOTERDijk, P. (2003) Esferas I. Burbujas. Madrid, Siruela.

Touraine, A. (1998-1999) De la antigua a la nueva sociología del trabajo. Sociología del Trabajo, 35, 3-23.

Trianes, M. ${ }^{2}$ V. (1996) Educación y competencia social. Archidona (Málaga), Aljibe.

TugendHAT, E. (1997) Lecciones de ética. Barcelona, Gedisa.

VÁzQuez, G. (2002) Los procesos de aprendizaje. La acción educativa como construcción de la persona, en BERNAL, A. (coord.). Persona, curriculum y postmodernidad. Barcelona, PPU, 63-94.

WEIGERT, A. J. (1983) Social psychology. A sociological approach through interpretive understanding. Notre Dame, U. of Notre Dame Press.

VERA, J. (2001) Influencia educativa de los medios de comunicación social en la sociedad neoliberal, Teoría de la Educación. Revista Interuniversitaria, 13, 187-208.

WEBER, M. (1980) El político y el científico. Madrid, Alianza.

WESTEN, D. (1985) Self and society: narcissism, collectivism and the development of morals. Cambridge, Cambridge University Press.

WHITE, R. W. (1987) Seeking the shape of personality: A memoir. Marlborough, N.H., Homestead Press. 